\title{
Erratum to: Amperometric biosensor for 5-hydroxymethylcytosine based on enzymatic catalysis and using spherical poly(acrylic acid) brushes
}

\author{
Wenjing Jiang ${ }^{1} \cdot$ Yun $\mathrm{Lu}^{2} \cdot$ Haiyan Wang ${ }^{1} \cdot$ Minghui Wang ${ }^{1} \cdot$ Huanshun Yin ${ }^{1}$
}

Published online: 29 August 2017

(C) Springer-Verlag GmbH Austria 2017

Erratum to: Microchimica Acta

https://doi.org/10.1007/s00604-017-2401-2

The original version of this article unfortunately contained a mistake in the list of authors. The name of corresponding author was wrong; it should be "Huanshun Yin" not "Hunshun Yin" Given in this article is the correct author name. The original article has been corrected.

The online version of the original article can be found at https://oi.org/ $10.1007 / \mathrm{s} 00604-017-2401-2$

\footnotetext{
Huanshun Yin

yinhs@sdau.edu.cn

1 College of Chemistry and Material Science, Shandong Agricultural University, Taian 271018, People's Republic of China

2 College of Foreign Languages, Shandong Agricultural University, Taian 271018, People's Republic of China
} 